\title{
Association between FbxI5 gene polymorphisms and partial economic traits in Jinghai Yellow chickens
}

\author{
Xuemei Yin ${ }^{1,2}$, Manman Yuan ${ }^{1,2}$, Yanjun Duan ${ }^{1,2}$, Shanshan Zhang ${ }^{1,2}$, Yulin Wu ${ }^{1,2}$, and Jinyu Wang ${ }^{1,2}$ \\ ${ }^{1}$ College of Animal Science and Technology, Yangzhou University, Yangzhou, Jiangsu, China \\ ${ }^{2}$ Institutes of Agricultural Science and Technology Development, Yangzhou University, Jiangsu, China
}

Correspondence: Jinyu Wang (jywang@yzu.edu.cn)

Received: 14 December 2018 - Revised: 25 February 2019 - Accepted: 5 March 2019 - Published: 20 March 2019

\begin{abstract}
The $F b x l 5$ gene is a member of the $F-B O X$ family and plays an important role in maintaining iron homeostasis in cells. In order to reveal the genetic effects of $F b x l 5$ gene polymorphisms on body weight (BW) traits and reproductive performance in chickens, Fbxl5 gene polymorphisms were detected in 363 Jinghai Yellow chickens by PCR-single-strand conformation polymorphism (SSCP) and DNA sequencing methods using three primers. With primer 1 , three genotypes $(\mathrm{BB}, \mathrm{bb}, \mathrm{Bb})$ were detected in the Jinghai Yellow chicken population and two mutations (g. $14257 \mathrm{~T}>\mathrm{C}$ and g. $14262 \mathrm{~T}>\mathrm{C}$ ) were revealed by gene sequencing. With primer 2 , two genotypes (EE, Ee) were detected in the same population and one mutation (g. $19018 \mathrm{G}>\mathrm{A}$ ), and for primer 3, three genotypes (FF, ff, Ff) and one mutation (g. $19018 \mathrm{G}>\mathrm{A}$ ) were detected. Four single nucleotide polymorphisms (SNPs) were used to estimate the frequency distributions of the eight haplotypes with PHASE 2.1 software. CTCG was the major haplotype with a frequency of $37.93 \%$, while the least frequent was TCTA with a frequency of $2.98 \%$. The BW of haplotype combination $\mathrm{H} 1 \mathrm{H} 8$ was higher than that of the other haplotypes and was a dominant combination. In terms of reproductive performance, the age at the first egg of the haplotype combination $\mathrm{H} 9 \mathrm{H} 1$ was later than in the other haplotypes, but the mean egg weight at 300 days was relatively optimal. The $\mathrm{H} 1 \mathrm{H} 2$ haplotype produced the highest mean egg weight in 300 days, although the total number of eggs in 300 days was smaller in the $\mathrm{H} 2 \mathrm{H} 4$ haplotype with the highest at first egg. Therefore, we can consider using the haplotype combination $\mathrm{H} 1 \mathrm{H} 2$ for selection. The findings of this study expand the theoretical basis of the use of the Fbxl5 gene in the molecular breeding of poultry.
\end{abstract}

\section{Introduction}

F-box and leucine-rich repeat protein 5 was discovered by Ruiz et al. (2014) using a database search method. It was first identified by Vashisht et al. (2009), using immunoprecipitation, as a subunit of SCF type E3 ubiquitin ligase, which belongs to the F-BOX family and encodes 691 amino acids. As one of the E3 ubiquitin enzymes, Fbx15 can mediate the transfer of activated ubiquitin molecules from the binding enzyme E2. Different ubiquitinated enzymes target different substrate proteins and determine the specificity of ubiquitination, so that related proteins can be specifically degraded (Darosa et al., 2015). It is also closely involved in the cell cycle, signal transduction, DNA repair, immune response, and DNA regulation (He et al., 2016).
Chen et al. (2014) found that the Fbxl5 gene plays an oncogenic role in lung cancer. High expression of Fbxl5 contributes to the occurrence and development of lung cancer. They also found that there was a negative correlation between the protein levels of HSSBI and Fbx15. The Fbxl5 gene targets HSSBI to mediate its ubiquitination and subsequent degradation, and to regulate the repair of DNA damage (Chen et al., 2014). Fbxl5 has been reported to function as a tumor suppressor in the regulation of cancer metastasis in cervical cancer and gastric cancer (Wu et al., 2015, 2016; Xiong et al., 2017). Other studies had shown that the primary role of the Fbxl5 gene was to mediate the subsequent interpretation of the ubiquitin iron regulatory proteins IRP1 and IRP2 through iron dependence, which plays a crucial role in maintaining iron homeostasis in cells (Ruiz et al., 2014). 
Table 1. Primer sequences of PCR amplification of the chicken Fbxl5 gene.

\begin{tabular}{lllrr}
\hline Primer & Position & Primers sequence $\left(5^{\prime}-3^{\prime}\right)$ & $\begin{array}{r}\text { Annealing } \\
\text { temp }\left({ }^{\circ} \mathrm{C}\right)\end{array}$ & Length (bp) \\
\hline P1 & exon 3 & $\begin{array}{l}\text { F:TGAATATGAACAGCTAAACTATGCG } \\
\text { R:CTTAGTCATTTCAAACACCAAGGA }\end{array}$ & 55.7 & 151 \\
\hline P2 & exon 4 & $\begin{array}{l}\text { F:TCAGGTTTTTCAGCCAATGTTGAT } \\
\text { R:CCTCACCTTGATCTGTCTTCTCG }\end{array}$ & 57.3 & 194 \\
\hline P3 & exon 5 & $\begin{array}{l}\text { F:AAGTAACCGGGCACACAACAA } \\
\text { R:ACTCAACTTCTGTAACTGACAACCT }\end{array}$ & 57.2 & 230 \\
\hline
\end{tabular}

Table 2. The results of haplotype analysis of the Fbxl5 gene.

\begin{tabular}{lrlr}
\hline No. & Number & Haplotype & Frequency $(\%)$ \\
\hline H1 & 267 & CTCG & 37.9312 \\
H2 & 46 & CTCA & 8.3894 \\
H3 & 138 & CTTG & 14.8831 \\
H4 & 40 & CTTA & 4.7909 \\
H5 & 90 & TCCG & 11.6207 \\
H6 & 134 & TCCA & 14.2434 \\
H7 & 17 & TCTG & 4.3504 \\
H8 & 6 & TCTA & 2.9844 \\
\hline
\end{tabular}

Using specific-locus amplified fragment sequencing (SLAF-seq) and a genome-wide association study (GWAS), we identified 19 single nucleotide polymorphism (SNP) loci that were significantly related to the growth of Jinghai Yellow chickens and mapped them to nine genes. We selected Fbxl5 as a candidate gene. At present, there are few studies on the Fbxl5 polymorphism and associated economic traits in chickens. Therefore, the aim of the present study was to investigate the contribution of the $F b x l 5$ gene to a wider range of performance traits in chickens, and, in particular, to confirm whether Fbxl5 gene polymorphisms exert a significant effect on body weight (BW) and reproductive performance at different ages.

\section{Materials and methods}

\subsection{Ethics statement}

The study protocol was approved by the Animal Care Committee of the Department of Animal Science and Technology of Yangzhou University and conducted in accordance with the guidelines of the Animal Use Committee of the Chinese Ministry of Agriculture. All efforts were made to minimize animal suffering.

\subsection{Population and sample collection}

A total of 363 female Jinghai Yellow chickens were selected randomly from the core group of 12 generations, which is a new breed of high quality broiler bred by Jiangsu Jinghai Poultry Group Co., Ltd, Yangzhou University and Jiangsu Province Animal Husbandry and Veterinary General Station. It has the advantages of identical physique, stable and excellent production and hereditary stability. All birds were hatched on the same day and reared on the ground under the same nutritional and environmental conditions. Nine growth traits, the $\mathrm{BW}$ of chickens at day $0(\mathrm{BW} 0)$ and weeks 2(BW2), 4(BW4), 6(BW6), 8(BW8), 10(BW10), 12(BW12), 14(BW14), 16(BW16) and five reproductive performance (age at first egg, weight at first egg, initial egg weight, weight in 300 days, mean egg weight in 300 days, total egg number in 300 days), were recorded. Genomic DNA was extracted by the phenolchloroform extraction method, dissolved in Trisethylenediaminetetraacetic acid (EDTA) buffer, then quantified by spectrophotometry and then stored at $-20^{\circ} \mathrm{C}$ until analyzed.

\subsection{Primer design and variability analysis}

According to the gallinaceous Fbxl5 gene sequences (GenBank Accession NO. NC_006091). Primer 5.0 software was used to design three pairs of primers to amplify fragments that encompassed exon 3, exon 4 and exon 5 of the Fbxl5 gene (Table 1). Primers were synthesized by Sangon Biotech (Shanghai) CO., Ltd. Polymerase chain reaction (PCR) was performend in a $20 \mu \mathrm{L}$ reaction volume containing $1 \mu \mathrm{L}$ of genomic DNA, $0.8 \mu \mathrm{L}$ of each primer, $7.4 \mu \mathrm{L}$ of $\mathrm{dH}_{2} \mathrm{O}$, and $10 \mu \mathrm{L}$ of $2 \times$ Taq Master Mix for polyacrylamide gel electrophoresis (Vazyme Biotech Co., Ltd., Nanjing, China). The PCR thermal profile consisted of pre-denaturation at $94{ }^{\circ} \mathrm{C}$ for $5 \mathrm{~min}$, followed by 30 cycles of denaturation at $94^{\circ} \mathrm{C}$ for $30 \mathrm{~s}$, annealing at $X^{\circ} \mathrm{C}$ for $30 \mathrm{~s}$, elongation at $72^{\circ} \mathrm{C}$ for $35 \mathrm{~s}$ and final extension at $72{ }^{\circ} \mathrm{C}$ for $10 \mathrm{~min}$, at last $4{ }^{\circ} \mathrm{C}$ forever ( $X$ is annealing temperature specific for the primer pairs; see Table 1).

For single-strand conformation polymorphism (SSCP) analysis, $2.5 \mu \mathrm{L}$ of each amplification product was mixed with $7.5 \mu \mathrm{L}$ of denaturing buffer, heated for $10 \mathrm{~min}$ at $98^{\circ} \mathrm{C}$ and then cooled on ice for $10 \mathrm{~min}$. Denatured PCR products were subjected to $10 \%$ non-denaturing polyacrylamide (29: 1) gel electrophoresis at $250 \mathrm{~V}$ for the first $5 \mathrm{~min}$ and 
then $120 \mathrm{~V} \mathrm{~cm}^{-1}$ for 10 to $12 \mathrm{~h}$. SSCP patterns on the gels were visualized by silver staining. For each genotype, Sangon Biotech sequenced the PCR product of four samples.

\subsection{Statistical analysis}

SHEsis software was used to analyze the genetic linkage disequilibrium at SNP locus and PHSAE 2.1 software was used to analyze the types and frequency of haplotypes. All statistical analysis was based on the General Linear Model (GLM) model of SPSS 19.0. The following statistical model was used:

$D^{\prime}=\frac{D}{D_{\max }}, D=P_{i j}-P_{i} P_{j}$,

when $D \geq 0, D_{\max }=\min \left(P_{i} P_{j},\left(1-P_{i}\right)\left(1-P_{j}\right)\right)$,

when $D<0, D_{\max }=\min \left(\left(1-P_{i}\right) P_{i}, P_{j}\left(1-P_{j}\right)\right)$,

$r^{2}=\frac{D^{2}}{P_{i}\left(1-P_{i}\right) P_{j}\left(1-P_{j}\right)}$.

$P_{i}$ : the frequency of $i$ allele; $\mathrm{P}_{j}$ : the frequency of $j$ allele; $\mathrm{P}_{i j}$ : the haplotype frequency that carries both $i$ allele and $j$ allele.

$Y_{i j}=\mu+G_{j}+e_{\mathrm{ij}}$,

where $Y$ is the phenotypic value of traits, $\mu$ the population mean, $G_{j}$ fixed effects of genotype or diplotype, and $e$ random residual error. Multiple comparisons were performed with least squares means.

\section{Results}

\subsection{SSCP and sequence analysis}

Single-strand conformation polymorphism (SSCP) analysis revealed that the products of the three primer pairs displayed polymorphisms in the Fbxl5 gene. Three genotypes were detected in Jinghai Yellow chickens with primer pair 1 (BB, bb, Bb; Fig. 1a), two with primer pair 2 (EE, Ee; Fig. 1b), and three with primer pair 3 (FF, ff, Ff; Fig. 1c).

The PCR products of different genotypes were cloned and sequenced. Sequencing revealed two nucleotide mutations (g. $14257 \mathrm{~T}>\mathrm{C}$ and g. $14262 \mathrm{~T}>\mathrm{C}$ ) for primer 1 (Fig. 2a). Sequencing analysis results of the different genotypes for primer 2 are depicted in Fig. 2b; there was one nucleotide mutation (g. $15751 \mathrm{~T}>\mathrm{C}$ ). The results also revealed one nucleotide mutation (g. 19018 G > A) for primer 3 (Fig. 2c). Because of the base substitution, the codon that encodes one amino acid transformed into a codon of another amino acid, translate into different amino acids, which named missense mutation. While with the exist of genetic codon merges, base mutation does not cause amino acid change, which called same-sense mutation. In this study, of all the mutation sites, there was only one (g. $14257 \mathrm{~T}>\mathrm{C}$ ) that caused anamino acid to change, in this case from leucine to proline, which was a missense mutation. Other mutation sites did not result in an amino acid change and so were same-sense mutations.

\subsection{Linkage disequilibrium analysis of $F b x / 5$ mutation sites in different exons}

SHEsis online analysis software was used to conduct the linkage disequilibrium analysis of four SNP loci. The results showed that there was a strong linkage disequilibrium between g. $14257 \mathrm{~T}>\mathrm{C}$ and g. $14262 \mathrm{~T}>\mathrm{C}\left(D^{\prime}>0.8\right.$, $r^{2}>0.33$ ) (Fig. 3). In the image, the red shade represents the depth of the linkage disequilibrium; the deeper the shade of red, the more obvious the linkage imbalance. When the $D^{\prime}$ value was greater than 0.8 , the red color was obvious. Values of a coefficient of determination $\left(r^{2}\right)$ greater than 0.33 denoted a strong linkage disequilibrium and were displayed in red.

\subsection{Haplotype analysis among mutation sites of $F b x / 5$}

Haplotypes and frequencies were analyzed by PHASE 2.1 software. In theory, the number of haplotypes detected in Fbxl5 should be 16; however, the number of haplotypes obtained using the software was actually 8 . The haplotypes with a frequency greater than $1 \%$ were named (Table 2).

\subsection{Correlation analysis between mutation site haplotype combinations and growth traits}

Correlation analysis between haplotype combinations of four mutation sites of Fbxl5 and growth traits in Jinghai Yellow chicken by SPSS software. Any haplotype combinations in which the number of individuals was less than three in this population were not discussed. The result showed that the weight of haplotype $\mathrm{H} 2 \mathrm{H} 8$ was higher than that of other haplotypes (Table 3 ). The BW0 of haplotype combinations $\mathrm{H} 1 \mathrm{H} 8$ and $\mathrm{H} 3 \mathrm{H} 8$ was significantly higher than that of the $\mathrm{H} 1 \mathrm{H} 1, \mathrm{H} 1 \mathrm{H} 3$ and $\mathrm{H} 3 \mathrm{H} 4$ combinations $(P<0.05)$. The BW12 of the haplotype combinations $\mathrm{H} 1 \mathrm{H} 3$ and $\mathrm{H} 1 \mathrm{H} 4$ was significantly higher than that of the H1H1 combination $(P<0.05)$, whereas the BW12 of haplotype combinations $\mathrm{H} 1 \mathrm{H} 8$ and $\mathrm{H} 3 \mathrm{H} 8$ was extremely significant, higher than those of the $\mathrm{H} 1 \mathrm{H} 1, \mathrm{H} 1 \mathrm{H} 3$, and $\mathrm{H} 1 \mathrm{H} 4$ combination $(P<0.01)$. The BW14 of haplotype combinations $\mathrm{H} 1 \mathrm{H} 3, \mathrm{H} 1 \mathrm{H} 4, \mathrm{H} 1 \mathrm{H} 8$ and $\mathrm{H} 3 \mathrm{H} 8$ was significantly higher than that of the $\mathrm{H} 1 \mathrm{H} 1$ combination $(P<0.05)$. The BW16 of haplotype combinations $\mathrm{H} 1 \mathrm{H} 8$ and $\mathrm{H} 3 \mathrm{H} 8$ was significantly higher than that of the $\mathrm{H} 1 \mathrm{H} 1$ combination $(P<0.05)$.

\subsection{Correlation analysis between mutation site haplotype combinations and reproductive performance}

The relationship between the haplotype combinations of four mutation loci of $F b x l 5$ and reproductive performance were 
(a)

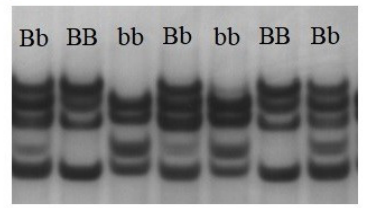

(b)

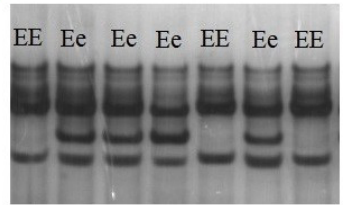

(c)

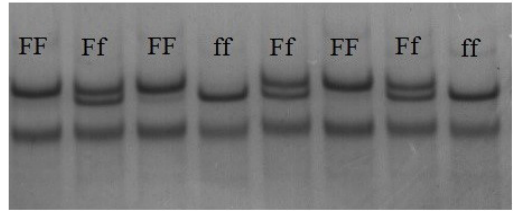

Figure 1. SSCP analysis of PCR amplification with three primers in Jinghai Yellow chicken.

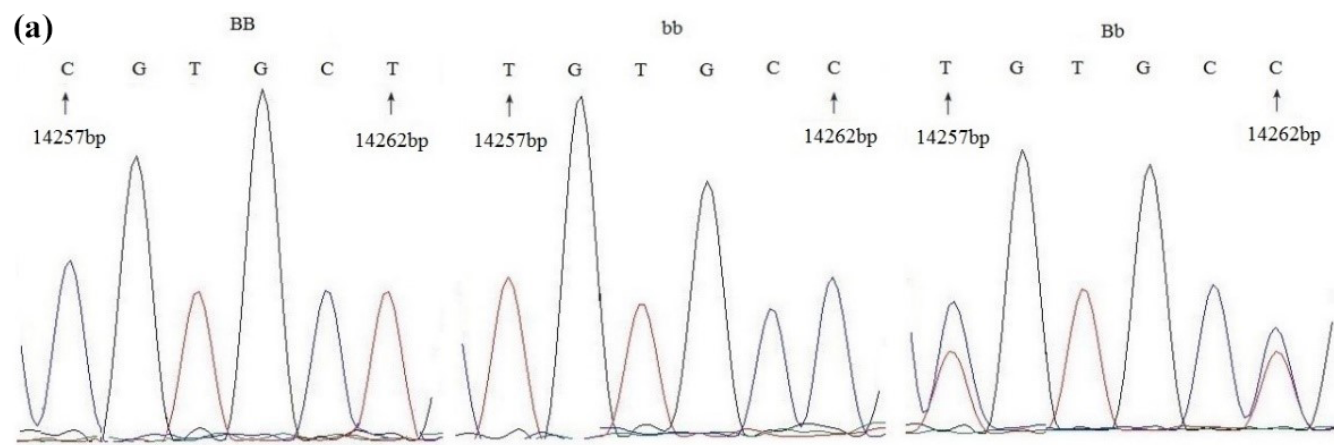

(b)
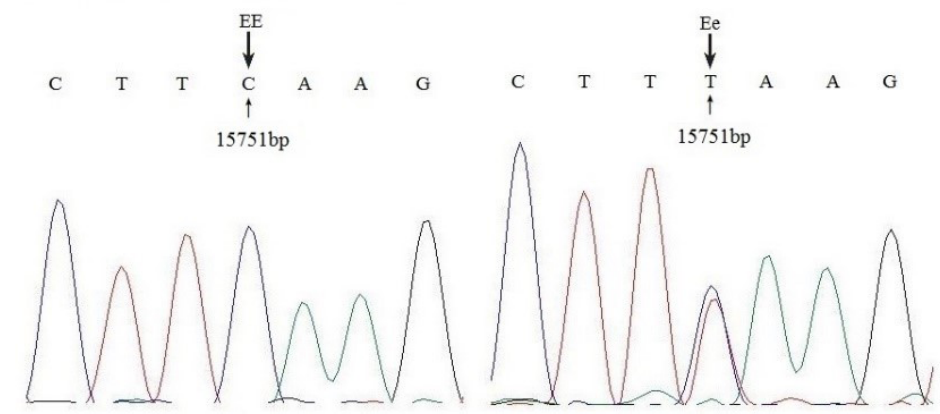

(c)

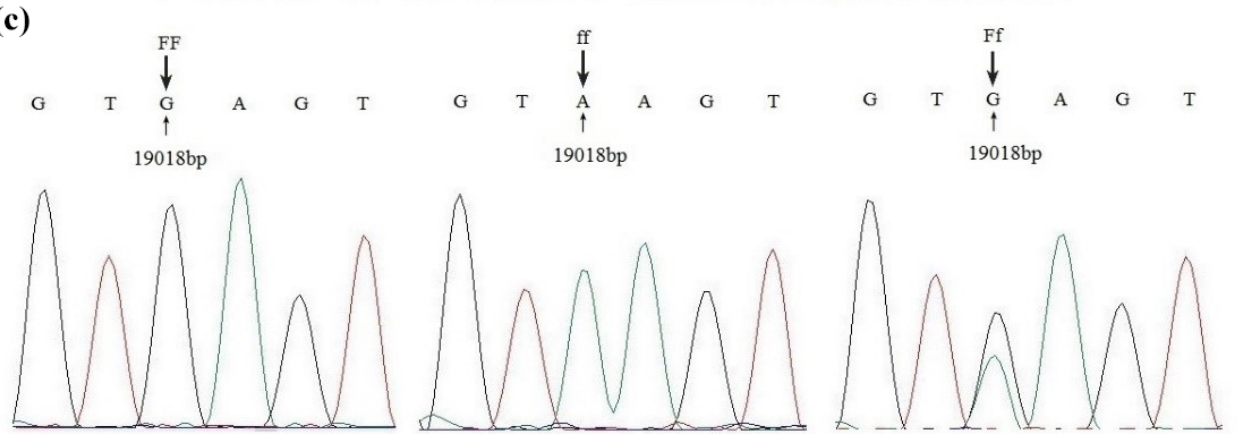

Figure 2. Sequence alignment of three primers with different genotypes in Jinghai Yellow chicken.

analyzed (Table 4). The results showed that the haplotype combination $\mathrm{H} 9 \mathrm{H} 11$ was highest in age at the first egg of all the haplotype combinations and was extremely significantly higher than that of the $\mathrm{H} 1 \mathrm{H} 1, \mathrm{H} 1 \mathrm{H} 3, \mathrm{H} 1 \mathrm{H} 4, \mathrm{H} 1 \mathrm{H} 8$ and H1H9 combinations $(P<0.01)$. At the same time, the age at the first egg of the haplotype combinations $\mathrm{H} 1 \mathrm{H} 3, \mathrm{H} 3 \mathrm{H} 8$, and $\mathrm{H} 8 \mathrm{H} 8$ was significantly higher than that of the $\mathrm{H} 1 \mathrm{H} 1$ combination $(P<0.05)$. The weight at the first egg of haplotype combination $\mathrm{H} 1 \mathrm{H} 2$ was the heaviest combination, and the weights at the first egg of haplotype combinations $\mathrm{H} 1 \mathrm{H} 2, \mathrm{H} 1 \mathrm{H} 3, \mathrm{H} 1 \mathrm{H} 4$ and $\mathrm{H} 1 \mathrm{H} 8$ were significantly higher than those of the $\mathrm{H} 8 \mathrm{H} 9$ and H9H9 combinations $(P<0.05)$. The initial egg weight of the haplotype combination $\mathrm{H} 2 \mathrm{H} 4$ was the highest, while that of H4H9 was the lowest. The initial egg weights of the haplotype combinations $\mathrm{H} 1 \mathrm{H} 1, \mathrm{H} 1 \mathrm{H} 3, \mathrm{H} 1 \mathrm{H} 4, \mathrm{H} 1 \mathrm{H} 8$, and $\mathrm{H} 2 \mathrm{H} 4$ were extremely significantly higher than that of the H4H9 combination $(P<0.01)$, and the initial egg weight of haplotype combination $\mathrm{H} 1 \mathrm{H} 9$ was significantly lower than those of the H1H8, H2H4, and $\mathrm{H} 9 \mathrm{H} 10$ combinations $(P<0.05)$. The weight at 300 days of haplotype combination $\mathrm{H} 1 \mathrm{H} 2$ was the highest, and the weights at 300 days of haplotype combinations $\mathrm{H} 1 \mathrm{H} 2, \mathrm{H} 1 \mathrm{H} 3$, and $\mathrm{H} 1 \mathrm{H} 8$ were extremely signifi- 

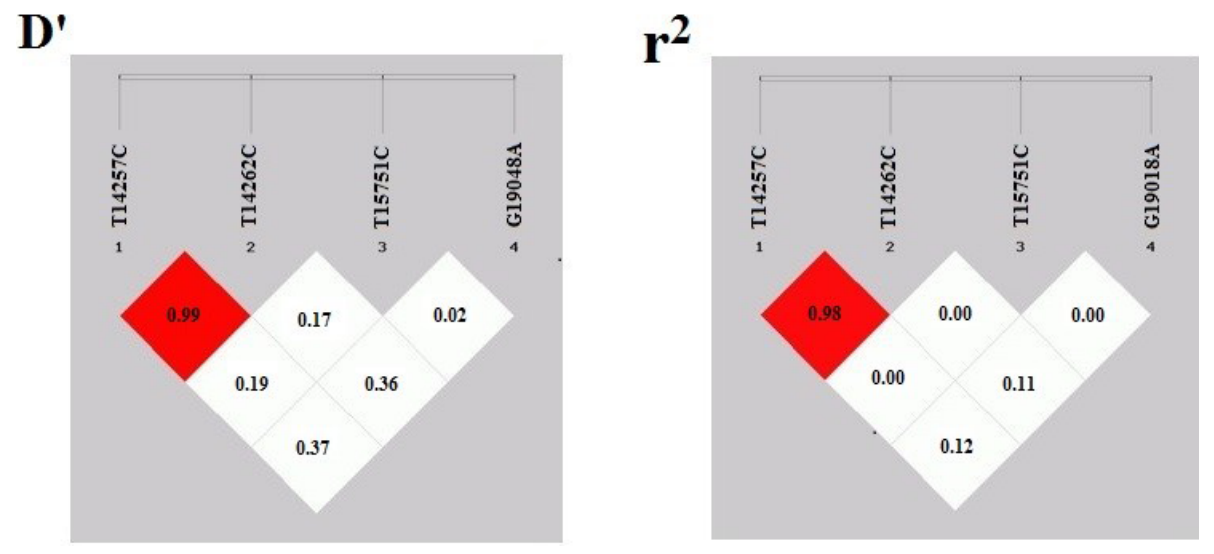

Figure 3. The linkage disequilibrium coefficient $D^{\prime}$ and $r^{2}$ map for the Fbxl5 gene in Jinghai Yellow chicken.

Table 3. Parameter estimates of Fbxl5 gene different genotypes on body weight traits (means \pm SD).

\begin{tabular}{lllllll}
\hline \multirow{2}{*}{$\begin{array}{l}\text { Weight } \\
\text { (g) }\end{array}$} & H1H1 & H1H3 & H1H4 & H1H8 & H3H8 & H8H9 \\
\cline { 2 - 7 } BW0 & $32.94 \pm 0.42^{\mathrm{b}}$ & $32.06 \pm 0.42^{\mathrm{b}}$ & $32.35 \pm 0.76^{\mathrm{b}}$ & $34.74 \pm 0.60^{\mathrm{a}}$ & $34.53 \pm 0.82^{\mathrm{a}}$ & $34.14 \pm 0.69$ \\
BW2 & $117.01 \pm 1.79$ & $116.41 \pm 2.09$ & $115.59 \pm 3.45$ & $117.89 \pm 2.69$ & $117.56 \pm 2.80$ & $117.50 \pm 3.73$ \\
BW4 & $244.56 \pm 3.93$ & $248.13 \pm 4.42$ & $252.64 \pm 6.48$ & $256.53 \pm 5.99$ & $250.62 \pm 6.29$ & $251.79 \pm 7.80$ \\
BW6 & $453.01 \pm 6.71$ & $460.60 \pm 6.88$ & $462.65 \pm 9.41$ & $472.89 \pm 10.89$ & $462.50 \pm 12.06$ & $445.71 \pm 12.60$ \\
BW8 & $586.03 \pm 8.05$ & $599.25 \pm 8.18$ & $605.59 \pm 11.24$ & $611.05 \pm 17.27$ & $605.94 \pm 14.84$ & $605.35 \pm 16.55$ \\
BW10 & $763.75 \pm 10.47$ & $784.18 \pm 9.72$ & $782.65 \pm 16.45$ & $797.37 \pm 11.94$ & $784.06 \pm 10.82$ & $769.69 \pm 15.74$ \\
BW12 & $936.03 \pm 12.31^{\mathrm{Bb}}$ & $960.42 \pm 10.09^{\mathrm{Ba}}$ & $961.18 \pm 12.07^{\mathrm{Ba}}$ & $963.94 \pm 16.98^{\mathrm{A}}$ & $962.50 \pm 9.59^{\mathrm{A}}$ & $940.71 \pm 11.32$ \\
BW14 & $1082.93 \pm 13.43^{\mathrm{b}}$ & $1114.48 \pm 12.41^{\mathrm{a}}$ & $1114.71 \pm 13.78^{\mathrm{a}}$ & $1117.47 \pm 12.14^{\mathrm{a}}$ & $1117.03 \pm 12.25^{\mathrm{a}}$ & $1106.43 \pm 12.33$ \\
BW16 & $1273.60 \pm 14.59^{\mathrm{b}}$ & $1304.46 \pm 13.62$ & $1326.76 \pm 14.53$ & $1333.42 \pm 13.07^{\mathrm{a}}$ & $1327.50 \pm 15.69^{\mathrm{a}}$ & $1282.14 \pm 13.30$ \\
\hline
\end{tabular}

Notes: means in the same row with different lowercases indicating significant difference $(P<0.05)$, with different capital letters indicating very significant difference $(P<0.01)$ and no letters indicating no differences $(P>0.05)$.

cantly higher than that of the H8H9 combination $(P<0.01)$. The mean egg weight at 300 days of the haplotype combination $\mathrm{H} 9 \mathrm{H} 11$ was the highest, and, with the exception of haplotypes $\mathrm{H} 2 \mathrm{H} 4$ and $\mathrm{H} 9 \mathrm{H} 9$, the other haplotype combinations were extremely significant $(p<0.01)$ or significantly different from one another $(P<0.05)$. The total egg number at 300 days was highest in haplotype combination $\mathrm{H} 1 \mathrm{H} 4$, and the total egg numbers from the haplotype combinations $\mathrm{H} 1 \mathrm{H} 3$ and $\mathrm{H} 1 \mathrm{H} 4$ were extremely significantly higher than that of the $\mathrm{H} 3 \mathrm{H} 8$ combination $(P<0.01)$.

\section{Discussion}

Iron is an essential element in the life of organisms. Iron in the animal body mainly exists in the form of heme iron and non-heme iron. Salahudeen et al. (2009) and Vashisht et al. (2009) reported that E3 ubiquitin ligase Fbxl5, with typical characteristics of F-BOX family proteins, had hemoglobin-like iron-binding regions and was a component of the SCF complex that can respond to intracellular iron levels. It participated in the regulation of iron metabolism through the degradation of the iron regulatory protein IRP2 by the ubiquitin proteasome system (Shen et al., 2012). Jiang et al. (2011) found that heme iron could increase the level of antibody in the blood and improve the disease resistance of laying hens. Gao et al. (2012) found that heme iron had a good growth-promoting effect on weaned piglets, and the blood hemoglobin and IgG concentrations of piglets were increased to some extent.

In this study, we scanned the SNPs in exon 3 , exon 4 and exon 5 of the Fbxl5 gene in Jinghai Yellow chickens. The products amplified by the Fbxl5 primer pairs 1, 2 and 3 displayed polymorphisms and four SNPs were identified by the sequencing of different PCR fragments, including two (g. $14257 \mathrm{~T}>\mathrm{C}$ and g. $14262 \mathrm{~T}>\mathrm{C}$ ) located in exon 3 that formed three genotypes (BB, bb, Bb), one (g. $15751 \mathrm{~T}>\mathrm{C}$ ) located in exon 4 that formed two genotypes (EE, Ee), and one (g. $19018 \mathrm{G}>\mathrm{A}$ ) located in exon 5 that formed three genotypes (FF, ff, Ff). The results indicated that the Fbxl5 gene had an abundance of polymorphisms in different animal breeds that conform to the comprehensive functions of the $F b x l 5$ gene. Linkage disequilibrium usually occurs in natural 


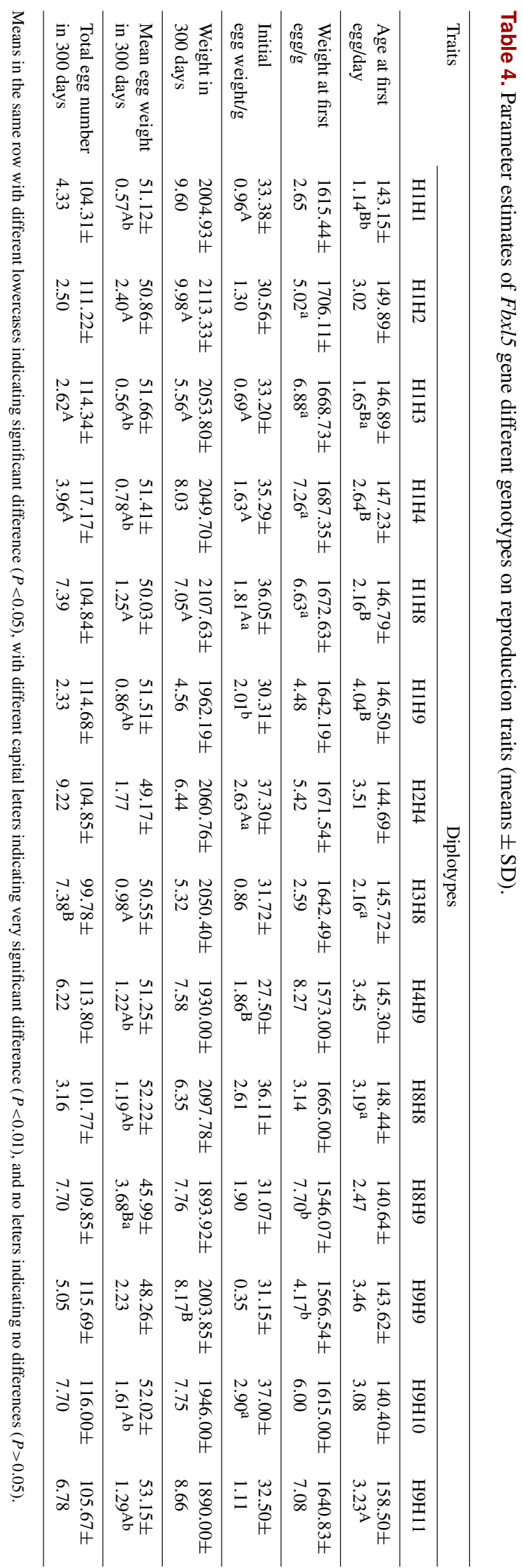

populations, often expressed in closely linked genes in offspring, so that adjacent SNP alleles are inherited to offspring as a bloc in haplotypes (Johnson et al., 2001). Linkage disequilibrium usually measured in terms of $D^{\prime}$ and $r^{2}$ (Jiang et al., 2004). The results from the current study showed that the two sites involved in the construction of the haplotypes were in strong linkage disequilibrium, $\left|D^{\prime}\right|>0.8, r^{2}>0.33$, indicating that the loci involved in the construction of haplotypes are closely linked to each other and are largely inherited a bloc (Ardlie et al., 2002; Guryev et al., 2006). Therefore, $r^{2}>0.33$ and $\left|D^{\prime}\right|>0.8$ can be used as a measure of strong disequilibrium. The linkage disequilibrium analysis of the four SNP loci detected on three exons of Fbxl5 gene was carried out; the results showed that there was a strong linkage disequilibrium between g. $14257 \mathrm{~T}>\mathrm{C}$ and g. $14262 \mathrm{~T}>\mathrm{C}$ $\left(D^{\prime}>0.8, r^{2}>0.33\right)$ in the core population of Jinghai Yellow chicken, which means that the two markers were closely linked. Therefore, we inferred that the two linked SNP loci may have a certain effect on the same traits.

The results showed that the combined haplotype analysis of multiple loci takes into account the interaction between non-alleles and the linkage disequilibrium prior to the SNP locus, so it has greater statistical potency (Horne et al., 2004). In this study, four SNP loci were found in three exons. There should be $2^{n}$ haplotypes in theory, but in fact there were eight effective haplotypes in this population $(P>0.01)$, which may be related to the existence of linkage disequilibrium, the density of the SNP site and the size of sample population. The results showed that only g. $14257 \mathrm{~T}>\mathrm{C}$ resulted in a change in amino acid encoded, from leucine to proline, among the several SNP sites found in the exon of the Fbxl5 gene. The other mutations did not cause amino acid change and are, therefore, same-sense mutations. Although the variation in these sites did not cause the change in individual amino acids, the results of haplotype association analysis showed that these polymorphisms caused changes in population growth and reproductive traits, which was consistent with previous studies (Wang et al., 2015).

The results indicated that the $F b x l 5$ gene had a significant effect on the growth and development of Jinghai Yellow chickens. Compared with other haplotypes, the body weight of haplotype combination H1H8 was higher than that of the other haplotypes and was a dominant combination, which is the combination that can be considered for selection. The age at which the first age was laid for haplotype combination H9H11 was the highest of all the haplotype combinations, and that for the haplotype combination H9H10 was the lowest of all the haplotype combinations. The weight at the first egg of haplotype combination $\mathrm{H} 1 \mathrm{H} 2$ and the initial egg weight of haplotype combination $\mathrm{H} 2 \mathrm{H} 4$ was a relatively superior combination. The weight at 300 days of haplotype combination $\mathrm{H} 1 \mathrm{H} 2$ and the mean egg weight at 300 days of haplotype combination H9H11 was the highest combination. The total egg number at 300 days of the haplotype combination $\mathrm{H} 1 \mathrm{H} 4$ was the relative optimal combination. It 
can be concluded that the H9H11 combination, which was the later than the other combinations in age at first age, was the best combination in mean egg weight at 300 days. The weight at 300 days of haplotype combination $\mathrm{H} 1 \mathrm{H} 2$ was the optimal combination. Whereas the total egg number in 300 days of the haplotype combination with best initial egg weight was smaller than that of other combinations. Therefore, the $\mathrm{H} 1 \mathrm{H} 2$ haplotype was regarded as the combination for selection. There was a significant negative correlation between body weight and reproductive performance of poultry. Therefore, in order to improve the potential of rapid and efficient growth and higher reproductive performance at the same time, there had been a number of measures to be taken to limit the amount of feeding (Robinson et al., 1993). Haplotype or haplotype block analysis provides a practical solution to resolving the innate problems of the single-marker analysis, such as noisy, unsatisfied, and obscured localization information (Daly et al., 2001). Both haplotype diversity and the method of SNP selection based on maximum haplotype diversity are always preferred (Huang et al., 2003).

Data availability. The datasets used and/or analyzed during the current study are available from the corresponding author on reasonable request.

Author contributions. $\mathrm{XY}$ and MY designed the experiments; $\mathrm{XY}, \mathrm{MY}$ and YD carried out the experiments; XY and SZ analyzed the experimental results; $Y D, S Z$ and $Y W$ analyzed sequencing data and developed analysis tools; XY wrote the manuscript; JW assisted with all.

Competing interests. The authors declare that they have no conflict of interest.

Acknowledgements. This work was supported by National Broiler Industrial and Technology System (no. nycytx-42-G1-05), China Agriculture Research System (CARS-41), Priority Academic Program Development of Jiangsu Higher Education Institutions.

Review statement. This paper was edited by Steffen Maak and reviewed by Tuncay Tufan and two anonymous referees.

\section{References}

Ardlie, K. G., Kruglyak, L., and Seielstad, M.: Patterns of linkage disequilibrium in the human genome, Nat. Rev. Genet., 3, 299309, 2002.

Chen, Z. W., Liu, B., and Tang, N. W.: Fbx15-mediated degradation of single-stranded DNA-binding protein hSSB1 controls DNA damage response, Nucleic Acids Res., 42, 11560-11569, 2014.
Daly, M. J., Rioux, J. D., and Schaffner, S. F.: High-resolution haplotype structure in the human genome, Nat. Genet., 29, 229-232, 2001.

Darosa, P. A., Wang, Z., and Jiang, X.: Allosteric activation of the RNF146 ubiquitin ligase by a poly(ADP-ribosyl)ation signal, Nature, 517, 223-226, 2015.

Gao, D. Y., Wang, L. X., and Yu, W.: Effects of heme iron on growth performance and blood biochemical parameters of weaned piglets, Feed Industry, 33, 24-26, 2012.

Guryev, V., Smits, B. M. G., and Belt, J. V. D.: Haplotype Block Structure Is Conserved across Mammals, PLoS Genet., 2, e121, 2006.

He, J. C.: The research progress on the relationship between E3 ubiquitin Fbxl 5 and malignant tumor, The Practical Journal of Cancer, 31, 520-522, 2016.

Horne, B. D. and Camp, N. J.: Principal component analysis for selection of optimal SNP-sets that capture intragenic genetic variation, Genet. Epidemiol., 26, 11-21, 2004.

Huang, Q. Q., Fu, Y. X., and Boerwinkle, E.: Comparison of strategies for selecting single nucleotide polymorphisms for case/control association studies, Hum. Genet., 113, 253-257, 2003.

Jiang, Y. M. and Yang, G. L.: Research and application of linkage disequilibrium, Jiangxi Plant Protection, 27, 61-63, 2004.

Jiang, G. Y., Pan, Y., and Gao, D. Y.: Effect of dietary heme iron on egg iron deposition and egg quality of layers, China Poultry, 33, 19-21, 2011.

Johnson, G. C., Esposito, L., and Barratt, B. J.: Haplotype tagging for the identification of common disease genes, Nat. Genet., 29, 233-237, 2001.

Robinson, F. E., Wilson, J. L., and Yu, M. W.: The Relationship between body weight and reproductive efficiency in meat-type chickens, Poultry Sci., 72, 912-922, 1993.

Ruiz, J. C. and Bruick, R. K.: F-box and leucine-rich repeat protein 5 (Fbx15): sensing intracellular iron and oxygen, J. Inorg. Biochem, 133, 73-77, 2014.

Salahudeen, A. A., Thompson, J. W., and Ruiz, J. C.: An E3 Ligase Possessing an Iron-Responsive Hemerythrin Domain Is a Regulator of Iron Homeostasis, Science, 326, 722-726, 2009.

Shen, J., Wang, F. D., and Hu, R. G.: Recent advance on crosstalk between iron metabolism and cellular protein ubiquitylation and degradation, Chinese Bulletin of Life Sciences, 24, 785-793, 2012.

Vashisht, A. A., Zumbrennen, K. B., and Huang, X. H.: Control of iron homeostasis by an iron-regulated ubiquitin ligase, Science, 326, 718-721, 2009.

Wang, W. H.: A genome-wide association study of growth, carcass and some disease-resistance traits on Jinghai Yellow Chicken, Yangzhou University, Yangzhou, 2015.

Wu, W., Ding, H., and Cao, J.: FBXL5 inhibits metastasis of gastric cancer through suppressing Snail1, Cell. Physiol. Biochem., 35, 1764-1772, 2015.

Wu, W. D., Wang, M., and Ding, H. H.: FBXL5 attenuates RhoGDI2-induced cisplatin resistance in gastric cancer cells, Eur. Rev. Med. Pharmaco., 20, 2551-2557, 2016.

Xiong, Y., Sun. F., and Dong, P. X.: iASPP induces EMT and cisplatin resistance in human cervical cancer through miR20a-FBXL5/BTG3 signaling, J. Exp. Clin. Canc. Res., 36, 48, https://doi.org/10.1371/journal.pgen.0020121, 2017. 